\title{
Synthesis Features of Iron Oxide Nanopowders with High Magnetic and Sorption Properties
}

Article in Materials Science Forum · January 2018

DOI: 10.4028/www.scientific.net/MSF.915.116

CITATIONS

0

5 authors, including:
READS

41

\section{A. G. Mamalis}

National Center for Scientific Research Demo. . 626 PUBLICATIONS 4,539 CITATIONS

SEE PROFILE

SEE PROFILE

\section{Vadym Starikov}

Kharkiv Polytechnical Institute

56 PUBLICATIONS 155 CITATIONS

SEE PROFILE

Some of the authors of this publication are also working on these related projects: 


\title{
Synthesis Features of Iron Oxide Nanopowders with High Magnetic and Sorption Properties
}

\section{Sergiy LAVRYNENKO ${ }^{1, a}$, Athanasios G. MAMALIS ${ }^{2, b}$, Dmitry SOFRONOV ${ }^{3, c}$, Alexandra ODNOVOLOVA ${ }^{3, d}$ and Vadym STARIKOV ${ }^{1, e}$}

\author{
${ }^{1}$ National Technical University "Kharkov Polytechnic Institute", Kharkov, Ukraine \\ 2Project Center for Nanotechnology and Advanced Engineering, NCSR "Demokritos", \\ Athens, Greece \\ ${ }^{3}$ State Scientific Institution "Institute for Single Crystals", National Academy of Sciences \\ of Ukraine, Kharkov, Ukraine

 \\ dodnovolova.alexandra@gmail.com, estarik@kpi.kharkov.ua
}

Keywords: iron oxide nanoparticles, magnetization, sorption, synthesis

\begin{abstract}
The magnetic particles of iron oxides are promising materials for the purification of water from ions of heavy metals and radionuclides. Their advantage compared to other sorbents is the ability to extract by applied magnetic field, which greatly simplifies the task of extraction, separation and processing in cleaning technologies. The aim of this work is investigation of temperature and concentration of iron in the solution effect on the phase composition, nanoparticle size and their magnetization.

Phase magnetite in the sample increases with increasing temperature and the magnetization decreases slightly with increasing the initial concentration of iron in solution. We found that regardless of the conditions of deposition formed spherical particles whose average size ranges from 7 to $15 \mathrm{~nm}$. The sorptive capacity of the particles is virtually independent of the phase composition and for cobalt is about $18 \mathrm{mg} / \mathrm{g}$. For sorption-based material magnetic particles Fe3O4 recommended to carry out the deposition process at a temperature not lower than $80^{\circ} \mathrm{C}$. The concentration of iron in solution must be within $0,15-0,3 \mathrm{M}$. The particles obtained contain in their composition at least $90 \mathrm{wt} . \%$ of magnetite phase and are characterized by a magnetization in the range of $65-70 \mathrm{~A} \cdot \mathrm{m} 2 / \mathrm{kg}$. Also in the paper is comparing efficiency of extraction and sorption capacity for cobalt particles by different phase of magnetite and hematite.
\end{abstract}

\section{Introduction}

Sorption extraction is one of the most effective and simple methods of purification of natural and waste waters from heavy metals and radionuclides [1,2]. Polymers [3], natural materials, oxides [4] were proposed to use as sorbents. In the latter group of materials iron oxides should be noted as components of effective sorption materials. Their advantage over other compounds consists in low cost of precursors, simplicity of synthesis, and in the fact that they exert no toxic effects on the human body [5].

Typically, the particles of iron oxide are produced by deposition from aqueous solution with a subsequent heat treatment at $200-600^{\circ} \mathrm{C}$. [6, 7].

It is well known that the functional properties of materials are largely determined by particle size and shape. For example, increasing the specifi c surface area of the sorbent leads to an increase in its sorptive capacity. Thus, in case of $\alpha-\mathrm{Fe}_{2} \mathrm{O}_{3}$ of a specifi c surface of $130 \mathrm{~m}^{2} \mathrm{~g}^{-1}$ the sorption capacity (at pH 3) for arsenic(V) and chromium(VI) was 51 and $30 \mathrm{mg} \mathrm{g}^{-1}$, respectively. A decrease in the specific surface area of up to $2 \mathrm{~m}^{2} \mathrm{~g}^{-1}$ led to a decrease in the sorption capacity of up to 0.30 and $0.37 \mathrm{mg} \mathrm{g}^{-1}$, respectively [8].

Thus, an issue of the effect of the conditions of particles producing on their morphological and functional characteristics is a topical. The nature of the anions is one of the factors exerting a significant effect on the formation of particles in deposition from aqueous solutions [9-12]. 


\section{Experimental Procedure}

\section{Synthesis of Fe2O3 particles}

Synthesis of $\mathrm{Fe} 2 \mathrm{O} 3$ particles as follows: $100 \mathrm{ml}$ of a $0.2 \mathrm{M}$ precursor salts of iron (III) an aqueous solution of ammonia or ammonium bicarbonate to a predetermined $\mathrm{pH}$ ranging from 7 to 12 and stirred on a magnetic stirrer for $30 \mathrm{~min}$. The resulting precipitate was filtered, washed several times with distilled water and dried at room temperature for $24 \mathrm{~h}$, then calcined at $450^{\circ} \mathrm{C}$ for 1 hour.

\section{Synthesis of $\mathrm{Fe}_{3} \mathrm{O}_{4}$ particles}

Synthesis of $\mathrm{Fe}_{3} \mathrm{O}_{4}$ particles was performed by precipitation from aqueous solution: $5.99 \mathrm{~g}$ $\mathrm{FeSO}_{4} \cdot 7 \mathrm{H}_{2} \mathrm{O}$ and $10.79 \mathrm{~g}$ of $\mathrm{FeCl}_{3} \cdot 6 \mathrm{H}_{2} \mathrm{O}$ was dissolved in $40 \mathrm{ml}$ of distilled water. The resulting solution was heated to $60^{\circ} \mathrm{C}$ and $10 \mathrm{ml}$ of $25 \%$ aqueous ammonia solution under constant magnetic stirring. The resulting precipitate was filtered and washed with distilled water. Then dried in air for 24 hours.

\section{The sorption properties}

Sorption is carried out in monocomponent heavy metal solution at $\mathrm{pH} 6.5$ with concentration of 10 $250 \mathrm{mg} / \mathrm{l}$. In a $100 \mathrm{ml}$ beaker the $50 \mathrm{ml}$ of model solution was adjusted by addition of nitric acid or aqueous ammonia solution to a predetermined $\mathrm{pH}$ 6.5. Solution $\mathrm{pH}$ was measured by the "150 $\mathrm{pH} "$ pH-meter with glass electrode ESL-63-07 and the auxiliary silver chloride electrode EVL1MZ. Then was added $0.1 \mathrm{~g}$ of the adsorbent and kept under stirring for 40 minutes. The process of sorption was performed every 10 minutes with $\mathrm{pH}$ control in the case of deviations exceeding $0.1 \mathrm{pH}$ units, respectively adjusted to predetermined values. The sorbent was filtered after sorption and the content of metals in the filtrate was determinated.

\section{Results and Discussion}

$\mathrm{X}$-ray analysis of the sample $\mathrm{Fe}_{2} \mathrm{O}_{3}$ showed that after annealing at $450^{\circ} \mathrm{C}$ formed $a$ - $\mathrm{Fe}_{2} \mathrm{O}_{3}$ (hematite). Unlike samples $\mathrm{Fe}_{2} \mathrm{O}_{3}$, for $\mathrm{Fe}_{3} \mathrm{O}_{4}$ samples $\mathrm{X}$-ray data is multiphase and contain magnetite $\left(\mathrm{Fe}_{3} \mathrm{O}_{4}\right)-70 \%$, maghemite $\left(\gamma-\mathrm{Fe}_{2} \mathrm{O}_{3}\right)-25 \%$ and goethite $(\mathrm{FeOOH})-5 \%$. The presence of impurity phases goethite and maghemite $\mathrm{Fe}_{3} \mathrm{O}_{4}$ samples associated with aging and is characteristic of the powders obtained from aqueous solutions.

Fig. 1 shows the photomicrographs of particles (a) $\mathrm{Fe}_{2} \mathrm{O}_{3}$ and (b) $\mathrm{Fe}_{3} \mathrm{O}_{4}$, obtained from aqueous solution and annealed at $450^{\circ} \mathrm{C}$.

It is established that from nitrate solutions formed shapeless large agglomerates of $50-200$ microns (Fig. 1a), consisting of spherical particles of Fe2O3 (specific surface Ssp $=150 \mathrm{~m} 2 / \mathrm{g}$ ). Introduction of chloride ions leads to the formation of solid particles of cubic and oval size of about $0.12-0.20$ microns $(\mathrm{Ssp}=30 \mathrm{~m} 2 / \mathrm{g})$. Sodium ion has no significant effect on the formation of particles $\mathrm{Fe} 2 \mathrm{O} 3$.

Unlike $\mathrm{Fe}_{2} \mathrm{O}_{3}, \mathrm{Fe}_{3} \mathrm{O}_{4}$ is not observed in the formation of large agglomerates and the powder is composed of spherical with a size of from $0.5 \mathrm{um}$ to several microns. The specific surface area of $\mathrm{Fe}_{3} \mathrm{O}_{4}$ was $130 \mathrm{~m}^{2} / \mathrm{g}$.

Fig. 2 shows the degree of extraction of metals from the $\mathrm{pH}$ of the particles $\mathrm{Fe}_{2} \mathrm{O}_{3}$ (Fig. 2(a) and (c)) and $\mathrm{Fe}_{3} \mathrm{O}_{4}$ (Fig. 2(b) and (d)).

As can be seen from Fig. 2, iron oxide particles effectively recovered europium (97\%), Ce (97\%) and copper (92\%). However, in an acidic medium using Fe2O3 particles as sorbents can achieve high degrees of recovery of these metals as compared with Fe $3 \mathrm{O} 4$ particles.

The maximum extraction for $\mathrm{Fe} 2 \mathrm{O} 3$ is observed at $\mathrm{pH} 5.5$, and for $\mathrm{Fe} 3 \mathrm{O} 4$ is optimal $\mathrm{pH}$ 6.5. Efficiency of extraction of cobalt and strontium increases with increasing $\mathrm{pH}$ and reached maximum values at $\mathrm{pH} 9$.

The highest efficiency of extraction occurs on the particles of $\mathrm{Fe} 3 \mathrm{O} 4$ and $95 \%$ to $68 \%$ cobalt, and strontium. 
Furthermore, for strontium in the $\mathrm{pH}$ range $4-7$, depending observed additional peak recoveries in the range of $\mathrm{pH} 5.2$ - 5.7, which is more pronounced on Fe2O3 particles, see Fig. 2(a).

The results of calculation by Langmuir's method shown in Table 1. As can be seen from the data, the size of the sorption capacity $\mathrm{Fe}_{2} \mathrm{O}_{3}$ particles with $150 \mathrm{~m}^{2} / \mathrm{g}$ specific surface for all investigated metals are higher than the sorbents based on $\mathrm{Fe}_{3} \mathrm{O}_{4}$ with $130 \mathrm{~m}^{2} / \mathrm{g}$ specific surface.

Table 1 Parameters of sorption isotherms of europium, cerium and copper particles $\mathrm{Fe}_{2} \mathrm{O}_{3}$ and $\mathrm{Fe}_{3} \mathrm{O}_{4}$

\begin{tabular}{|c|c|c|c|c|c|c|}
\hline \multirow{2}{*}{ Metal } & \multicolumn{3}{|c|}{$\mathrm{Fe}_{2} \mathrm{O}_{3}$} & \multicolumn{3}{c|}{$\mathrm{Fe}_{3} \mathrm{O}_{4}$} \\
\cline { 2 - 7 } & $\mathrm{K}$ & $\mathrm{A}_{\infty},[\mathrm{mg} / \mathrm{g}]$ & $\mathrm{R}^{2},[\%]$ & $\mathrm{K}$ & $\mathrm{A}_{\infty},[\mathrm{mg} / \mathrm{g}]$ & $\mathrm{R}^{2},[\%]$ \\
\hline $\mathrm{Eu}$ & 0.007 & 21.3 & 89.85 & 0.024 & 19.7 & 92.97 \\
\hline $\mathrm{Ce}$ & 0.346 & 9.2 & 94.83 & 0.162 & 7.5 & 90.52 \\
\hline $\mathrm{Cu}$ & 0.029 & 15.7 & 94.12 & 0.039 & 11.66 & 93.57 \\
\hline
\end{tabular}

The highest sorption capacity is observed for the europium $-21.3 \mathrm{mg} / \mathrm{g}$ and $19.7 \mathrm{mg} / \mathrm{g}$ on the particles of $\mathrm{Fe}_{2} \mathrm{O}_{3}$ and $\mathrm{Fe}_{3} \mathrm{O}_{4}$, respectively, and the lowest - cerium on the particles of $\mathrm{Fe}_{2} \mathrm{O}_{3}$ $(9,2 \mathrm{mg} / \mathrm{g})$ and $\mathrm{Fe}_{3} \mathrm{O}_{4}$ particles $(7.5 \mathrm{mg} / \mathrm{g})$.
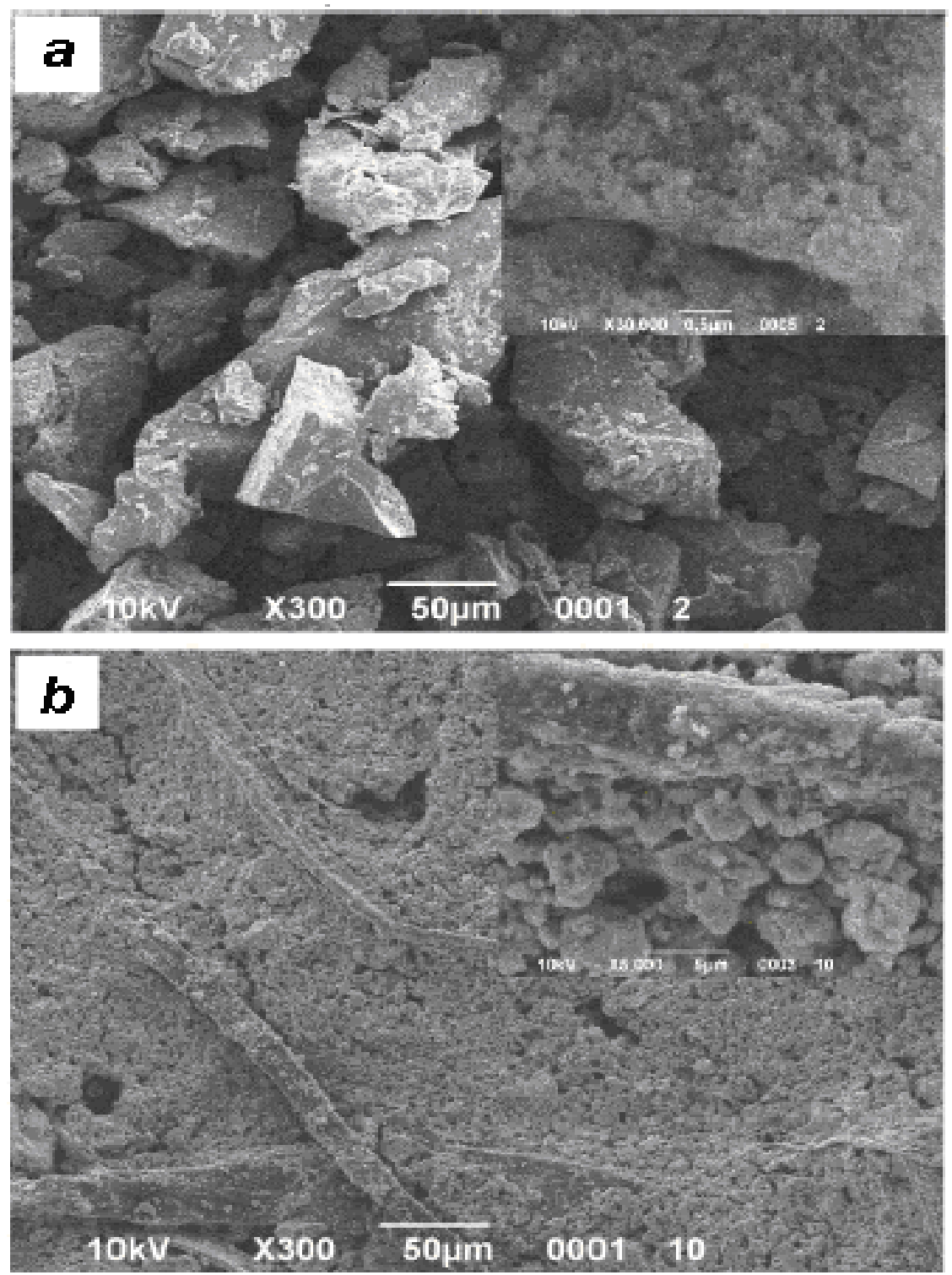

Fig. 1 Micrographs of particles (a) $\mathrm{Fe}_{2} \mathrm{O}_{3}$, (b) $\mathrm{Fe}_{3} \mathrm{O}_{4}$ annealed at $450^{\circ} \mathrm{C}$ 

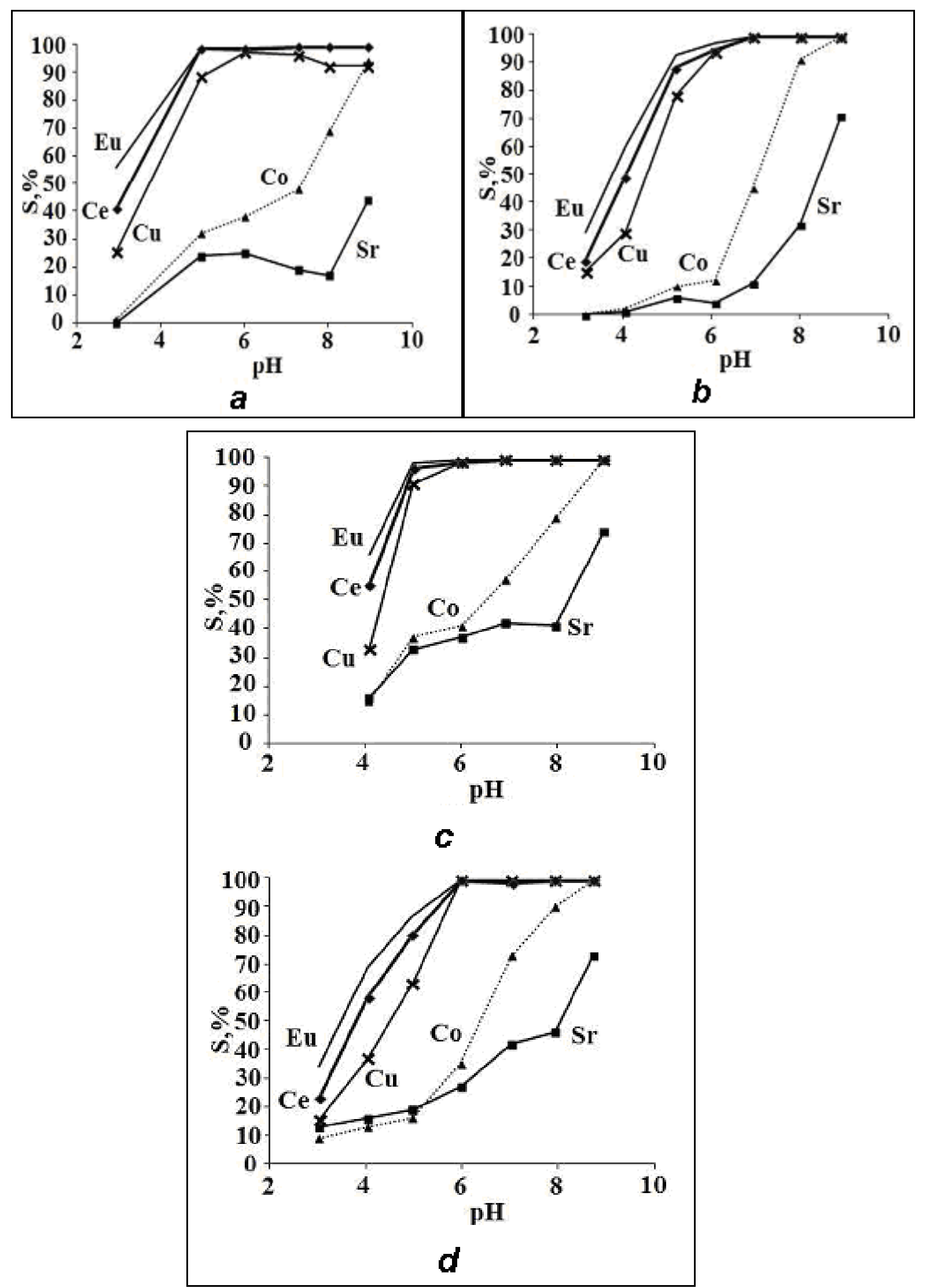

Fig. 2 Dependence of the degree of extraction of metals from the pH of the particles: (a) and (c) $\mathrm{Fe}_{2} \mathrm{O}_{3}$; (b) and (d) $\mathrm{Fe}_{3} \mathrm{O}_{4}$ 


\section{Summary}

(a) The effect of the deposition conditions (temperature, concentration of iron in solution) on the phase composition, particle size and magnetization. A comparison of the efficiency of extraction and sorption capacity of heavy metals in phase magnetite and hematite.

(b) It was found that the formation of magnetite phase is significantly affected by the deposition temperature. The higher the temperature, the greater the amount of magnetite phase in the sample. Carrying out the synthesis at $90^{\circ} \mathrm{C}$ in a $0.15 \mathrm{M}$ solution promotes formation of iron powder containing phase magnetite $\left(\mathrm{Fe}_{3} \mathrm{O}_{4}\right) 100 \mathrm{wt} . \%$

(c) Regardless of the deposition conditions form spherical particles having an average size ranging from 7 to $15 \mathrm{~nm}$.

(d) Raising the deposition temperature and reducing the concentration of iron in the solution contributes to obtaining a powder with larger particles that are characterized by higher value of magnetization.

\section{References}

[1] S.W. Park and C.P. Huang, J. Colloid a. Interface Sci., 128(1)(1989), 245-257

[2] G.V. Myasoedova and V.A. Nikishina, Ros. Khim. Zh., 1(5)(2006), 55-63

[3] I.A., Kovalev, N.M. Sorokina and G.I. Tsizin, Vestn. MGU. Khimiya, 41(5)(2000), 30-314

[4] A.S. Shilina and V.K Milinchuk, Sorb. Khromatogr. Prots, 10(2)(2010), 237-245

[5] Yao-Hui Huang, Chan-Li, Hsueh, Hui-Pin Cheng, et al., J. Materials, 144(2007), 406-411

[6] Y. Dong and X. Tian X, J. Non-Crystall. Solids, 356(2010), 1404-1407

[7] O.S. Petrova, A.E. Chekanova, E.A. Gudilin, et al., Int. Sci. J. Alternative Energy and Ecology, 45(1)(2007), 70-73

[8] Chang-Yan, Cao, Jin Qu, Wen-Sheng, Yan, et al., Langmuir, 28(2012), 4573-4579

[9] D.S. Sofronov, E.M. Sofronova, V.N. Baumer, et al., Advanced Powder Technol., 24(6)(2013), 1017-1022

[10] D.S Sofronov, E.M. Sofronova, V.N. Baumer, et al., Functional Materials, 18(2011), 523-528

[11] D.S Sofronov, D.S., N.N Kamneva, A.V. Bulgakova, et al., J. Biol. Phys. and Chem., 13(2013), 85-89

[12] A.M. Odnovolova, D.S. Sofronov, P.V. Mateichenko, et al. Russian J. of Appl. Chem., 87(8) (2014), 1060-1064 